\title{
Do Stereotypes Explain Discrimination Against Minority Candidates or Discrimination in Favor of Majority Candidates?
}

\author{
Lea Portmann* (D) \\ Department of Political Science, University of Lucerne, Switzerland \\ *Corresponding author. E-mail: lea.portmann@unilu.ch
}

(Received 5 November 2019; revised 28 October 2020; accepted 19 November 2020; first published online 2 March 2021)

\begin{abstract}
Scholars have examined the role that negative stereotypes play in electoral discrimination against minority candidates. Incorporating literature on in-group favoritism, the author argues here that some degree of this discrimination can be explained instead by voters holding positive stereotypes of majority candidates and discriminating in their favor. Based on the results of an original moderation-of-process survey experiment carried out in Italy, the study provides evidence of electoral discrimination pertaining to immigrantorigin candidates, concentrated among right-wing citizens. It finds that stereotypes have little mediating effect on discrimination against candidates with a migration background; rather, the primary role played by stereotypes is in discrimination in favor of majority candidates, that is, positive bias that reserves electoral benefits to them. The relevance of in-group favoritism is corroborated by the finding that large segments of the Italian voting population hold distinctively positive stereotypes of majority candidates without also negatively stereotyping immigrant-origin candidates.
\end{abstract}

Keywords: electoral discrimination; in-group favoritism; minority candidates; stereotypes; survey experiment

Individuals of immigrant origin in European democracies are increasingly being granted legal citizenship and thereby full rights to run as candidates for political office. A burgeoning literature shows that a considerable segment of voters, predominantly on the political right, is reluctant to vote said candidates into office (Besco 2020; Fisher et al. 2015; Portmann and Stojanović 2019; Street 2014; Thrasher et al. 2017). Such electoral discrimination on the part of voters contributes to the enduring under-representation of the population with a migration background (Dancygier et al. 2015; Sobolewska 2013), and challenges the premise of political equality that lies at the heart of liberal democracies (Dahl 2006).

As there is growing evidence of discrimination against immigrant-origin candidates across contexts, understanding the nature of electoral discrimination and voters' underlying psychological-cognitive processes is fundamental to advancing this field of research (see also Sobolewska 2017). I take a step toward this goal by incorporating literature on in-group favoritism from social psychology into the study of electoral discrimination. This literature shows that 'discrimination occurs more often as differential favoring than as differential harming' (Greenwald and Pettigrew 2014, 670). Specifically, I analyze the explanatory role of stereotypes in two distinct forms of discrimination, one rooted in out-group hostility (discrimination against immigrant-origin candidates) and the other arising from in-group favoritism (discrimination in favor of majority candidates). The latter form of discriminatory behavior is expressed by reserving electoral benefits to candidates and is expected to arise from voters who positively stereotype majority candidates. 
It is 'one of the most well-supported psychological findings' that people tend to be positively biased toward members of their own group (Fischer and Derham 2016, 1; see also Brewer 2017; Greenwald and Pettigrew 2014; Jardina 2020; Tajfel 1970; see Balliet, Wu and De Dreu 2014; Mullen, Brown and Smith 1992 for meta-analyses). Hundreds of studies on in-group favoritism have revealed the prevalence of such a positive bias regarding attitudes as well as with respect to behaviors (Brewer 2017, 90). In terms of attitudes, empirical research shows that stereotypes beliefs about the characteristics and attributes of social groups - often consist of associating positive characteristics more with an in-group (for example, in the United States, white Americans) than with an out-group (for example, African Americans) (Dovidio, Mann and Gaertner 1989; Gaertner and McLaughlin 1983; Hamley et al. 2020). Regarding behavior, individuals tend to allocate more resources (such as monetary endowments) to in-group compared to out-group individuals; that is, they discriminate in favor of in-group members (De Dreu 2010; Shah, Brazy and Higgins 2004). Social psychological research furthermore suggests that in-group favoritism is not only more prevalent than out-group hostility (Greenwald and Pettigrew 2014), but that the two forms of biases are also theoretically and empirically distinguishable. Specifically, this literature shows that they form at different stages in the development process, with in-group favoritism forming first (Buttelmann and Böhm 2014); correlate with specific individual-level characteristics (Bizumic et al. 2009; De Dreu 2010; Shah, Brazy and Higgins 2004); and tend to exist independently of each other (Brewer 2017; Buttelmann and Böhm 2014).

The electoral behavior literature has largely ignored the role of in-group favoritism (for important recent exceptions in the US context, see Jardina 2019; Jardina 2020; Petrow, Transue and Vercellotti 2018). Instead, explanations for electoral discrimination have focused on negative attitudes and behaviors directed toward out-group minority candidates. In line with this view, several studies have suggested that negative stereotypes of minority candidates' traits, beliefs and expected behavior in office can motivate discrimination (for example, McDermott 1998; Piston 2010; Van Trappen, Devroe and Wauters 2020).

I conducted an original survey experiment among Italian voters $(n=1,943)$ to investigate how stereotypes mediate two types of discrimination - one attributed to in-group favoritism and the other rooted in out-group hostility. Italy represents an interesting case for analysis, considering the significant rise in immigration in the last 30 years. A notable spike in negative attitudes toward immigrants in Italy has coincided with the sharp increase in immigration from the Middle East that began with the so-called European refugee crisis in 2015. Although immigrant-origin individuals are increasingly visible as candidates on Italian party ballots, they remain notably under-represented in political office (Vintila and Morales 2018).

While the standard approach of similar studies has been to measure stereotypes as a mediator (see, for example, Piston 2010; Van Trappen, Devroe and Wauters 2020), I opted for a moderation-of-process experiment that randomly manipulates candidate names (Italian or Algerian) as well as the mediator (see also Campbell et al. 2019). The latter is manipulated by presenting information about the candidates that contradicts stereotypical characteristics regarding personal traits and civic citizenship. According to stereotype-based explanations, this information should over-ride inferences drawn by voters based on stereotypes, thereby decreasing the effect of candidate names. Following advice in the literature on in-group favoritism, I measure discrimination not only as the probability that respondents will vote for a candidate, but also via a second measurement that includes an important tweak, capturing favorable, neutral and hostile behavior toward candidates (see Greenwald and Pettigrew 2014, 676; Hewstone, Rubin and Willis 2002). Specifically, respondents were provided three options with regards to the candidate: allocating a positive rating (connoting 'discrimination in favor of'), allocating a negative rating ('discrimination against') or refraining from giving a rating. Furthermore, I use latent profile analysis to disentangle the relationship between positive and negative stereotypes and their prevalence in the Italian population. 
The results from the experiment show, in line with previous studies in other countries (Besco 2020; Portmann and Stojanović 2019; Street 2014), that electoral discrimination occurs, albeit mainly concentrated among right-wing Italian citizens. Contrary to previous assumptions, I find no clear evidence that stereotypes mediate discrimination against candidates with a migration background. Strikingly, among the ideologically right-wing voters who are the main locus of discrimination, stereotypes primarily mediate discrimination in favor of majority candidates. This pattern suggests what has previously been overlooked: that while stereotypes matter in elections, they mostly explain voters' tendency to reserve benefits to majority candidates. The significance of in-group favoritism is further highlighted by the results of a latent profile analysis which reveal that a large share of Italian citizens hold positive stereotypes of majority candidates without negatively stereotyping immigrant-origin candidates.

The findings of this study have major implications regarding strategies to reduce discrimination in elections. The results highlight the importance of measures to address out-group bias as well as voters' reluctance to extend favorable evaluations and behavior to minority candidates. Parties and the media can help alleviate in-group electoral favoritism by priming the positive characteristics of immigrant-origin candidates or propagating an inclusive definition of who belongs to the in-group.

\section{Stereotypes and Voter Behavior}

I follow an extensive body of literature which maintains that discrimination in elections occurs because voters stereotype candidates based on their social group (for example, gender, race, ethnicity) (Piston 2010; Van Trappen, Devroe and Wauters 2020; Visalvanich 2017; for an overview see Block 2019). While stereotypes refer to attitudes, discrimination captures behavior. Stereotypes are defined as widely shared beliefs and attitudes about the characteristics of a given social group and individuals associated with that group (Dovidio et al. 2010, 8; Lippmann 1922). Discrimination constitutes 'differential treatment' based on an individual's membership in a 'socially salient group' (Lippert-Rasmussen 2018, 2; see also Allport 1954; Oskooii 2020). This study focuses on minority candidates with a migration background.

\section{Positive In-Group Stereotypes and Discrimination in Favor of Majority Candidates}

Many scholars have focused on negative stereotypes about minority candidates, assuming that stereotypes 'represent prejudice in its cognitive aspect' (Kinder 2013, 822). But stereotypes may be more 'complex' - not necessarily an expression of hostility, and 'less overtly negative' than has often been assumed (Gaertner and McLaughlin 1983, 30). An extensive literature in social psychology (mostly focusing on the United States) shows that stereotypes predominantly take the 'mild form' of in-group favoritism, rather than out-group hostility (Hewstone, Rubin and Willis 2002, 579; see also Gaertner et al. 1993; Greenwald and Pettigrew 2014; Hamley et al. 2020). This is compatible with findings from Europe suggesting that today, 'evaluative attitudes toward minorities have a positive as well as negative pole' and that many 'think well of minorities' (Sniderman et al. 2014, 121, 140). However, people with a migration background may still receive less positive evaluations than those without such a background.

Applied to the electoral context, these findings suggest that positive stereotypes of in-group majority candidates may be more prevalent than negative stereotypes of out-group minority candidates. At this point, it is important to emphasize that I am not assuming that these stereotypes are limited to majority voters; individuals of immigrant origin can also hold positive in-group or negative out-group stereotypes. However, candidates with a migration background, because of their minority status in the population, will be most detrimentally affected by these stereotypes.

Positive stereotypes of majority candidates (in-group favoritism at the attitudinal level) are expected to lead voters to discriminate in favor of said candidates (in-group favoritism at the behavioral level) (Brewer 2017; Greenwald and Pettigrew 2014; Hewstone, Rubin and Willis 
2002). Such discrimination in favor of majority candidates occurs when voters reserve benefits (such as actions that express explicit support) to candidates of their in-group (Brewer 2017; Greenwald and Pettigrew 2014; Magni 2020). Minority candidates, therefore, face a disadvantage not only because majority voters discriminate against them, but because voters discriminating in favor of majority candidates effectively penalize them. Most research on voter behavior has not distinguished between the two forms of discriminatory behavior (for a recent exception, see Portmann and Stojanović 2021). This is surprising, given the extensive literature in social psychology which shows that 'much intergroup discrimination takes the form of ingroup favoritism' (Brewer 2017, 90). Hence, in this article I assess the impact of stereotypes on pro-in-group behavior separately from their influence on action against candidates of the out-group. These arguments yield the following hypotheses:

Hypothesis 1: Voters discriminate in favor of majority candidates relative to those with a migration background.

Hypothesis 2: Stereotypical beliefs mediate discrimination in favor of majority candidates.

To what extent are in-group favoritism (positive stereotypes and discrimination in favor of majority candidates) and out-group hostility (negative stereotypes and discrimination against candidates with a migration background) different phenomena? Sniderman et al. $(2000,146)$ note that '[e] thnocentrism, classically conceived, yokes together outgroup hostility and ingroup identification. Perhaps the two terms should be uncoupled'. In line with this claim, Brewer (2017) argues that intergroup biases can (theoretically) be divided into the portion which is due to relative favorability toward in-group members and the share that stems from negativity toward members of the outgroup. This theoretical claim is corroborated by extensive empirical research (for example, De Figueiredo and Elkins 2003; Dovidio, Mann and Gaertner 1989; Gaertner and McLaughlin 1983; Greenwald and Pettigrew 2014; Hamley et al. 2020). For instance, based on a series of studies, Mummendey and Otten $(1998,117)$ note that '[p]ositive comparisons, which result in the ingroup being "better than" the outgroup, seem to be different from those which mean being "less bad"'. Other research emphasizes the conditional relationship between these two intergroup biases and argues that only under certain circumstances does in-group favoritism lead to out-group hostility (Brewer 1999, 430). This may occur in a situation in which losses for the outgroup are perceived as beneficial to the in-group. Moreover, in-group favoritism even occurs when the out-group is not explicitly specified (Brewer 2017). Taken together, we may conclude that in-group favoritism can, under certain conditions, lead to out-group hostility - but it far from implies it. Based on this literature, I argue that in-group favoritism toward majority candidates can - and should be - distinguished from out-group hostility targeted at minority candidates.

The importance of this distinction is further highlighted by findings showing that individuallevel characteristics that correlate with in-group favoritism are quite different from those related to out-group hostility (Brewer 2017; Hamley et al. 2020). Prior studies have revealed that a social value orientation and devotion are associated with in-group favoritism, but are not related to outgroup hostility and intergroup conflict (Bizumic et al. 2009; De Dreu 2010; Shah, Brazy and Higgins 2004). By contrast, individuals' belief in the superiority of their own group and desire for security predict out-group hostility, yet are not linked to in-group favoritism (Bizumic et al. 2009; Shah, Brazy and Higgins 2004). These findings indicate that strategies designed to tackle in-group favoritism must address other aspects of bias than those focusing on combating out-group hostility.

Three recent and notable studies incorporate in-group favoritism within an explanation of electoral behavior, with a focus on the US context (Jardina 2019; Jardina 2020; Petrow, Transue and Vercellotti 2018). Their core theoretical argument is that a common white identity - activated when white voters believe their status as members of a dominant group is threatened is prevalent in the electorate. Voters with a strong white in-group identity tend to support policies 
and candidates that they believe represent the interests of the white population - primarily, candidates who themselves belong to this social group. Unlike these studies, I assess voters' positive stereotypes of the in-group to explain discrimination in favor of majority candidates.

\section{Electoral Discrimination and Voters' Ideological Position}

Recent studies suggest that different blocs of voters contribute to varying degrees to discrimination against immigrant-origin candidates. In particular, electoral discrimination differs according to a voter's party preference and ideological positioning. Empirical studies show that candidates with a migration background face negative consequences mainly when they appear on right-wing party lists (Besco 2020; Janssen 2020; Portmann and Stojanović 2019; Street 2014). This can presumably be explained by the prevalence of negative attitudes toward minorities among right-wing parties and their supporters (Besco 2020, 2; Ivarsflaten, Blinder and Bjånesøy 2020). I incorporate insights from this research by analyzing discrimination and the mediating effect of stereotypes separately for different groups based on the ideological position of voters.

\section{The Italian Context}

Immigration to Italy has - in comparison to many western and northern European countries been a relatively recent phenomenon. Over the last 30 years, the country has experienced a considerable rise in the number of immigrants, mostly from Eastern Europe (Romania, Albania, Poland), North Africa (Morocco, Egypt, Algeria), Asia (China, Philippines) and Latin America (Brazil, Argentina) (Levy 2018, 51; Venturini 2004). Since the beginning of the 'European refugee crisis' in 2015, immigration has further increased, notably from the Middle East and Africa (Castelli Gattinara 2017, 318). Today, Italy is a multicultural country in which people from all corners of the world live, including over one million Muslims (Levy 2018, 49). As a result, both the foreign-born share of the population (10.4 per cent) and the number of naturalizations in Italy (1.9 per 1,000 residents in 2018 and more than 2 per cent of the resident population since 1998) are rapidly growing. ${ }^{1}$

Several indicators in different public opinion surveys suggest that anti-immigrant attitudes in Italy are comparable to - or, since the onset of the 'refugee crisis', slightly more widespread than - those in other European countries (Castelli Gattinara 2017, 322-324). Yet a large share of the Italian population also supports policies concerning citizenship and voting rights for foreigners that facilitate the political inclusion of people with a migration background (Vintila and Morales 2018, 533).

Are Muslim immigrants perceived to be particularly problematic? Contrary to what one might expect, Muslim immigrants (from North Africa in particular) are in socio-cultural terms well integrated in Italy compared to immigrants from other regions (Fokkema and de Haas 2011, 13). Nevertheless, the hostility toward Muslim immigrants that has increased across Europe in recent years is also prevalent in Italy (Castelli Gattinara 2017, 324). This may be partly explained by the Catholic Church's relatively strong presence in Italian society and politics, which may perpetuate a common Italian self-perception or national identity as white and Catholic (Levy 2018, 49).

The country's population with a migration background is significantly under-represented in Italian politics (Vintila and Morales 2018). ${ }^{2}$ In the legislative period from 2008 to 2013, only 1.5 per cent of the members of the national parliament had a migration background, compared

\footnotetext{
${ }^{1}$ See https://data.oecd.org/migration/foreign-born-population.htm, https://ec.europa.eu/eurostat/statistics-explained/index. php/Acquisition_of_citizenship_statistics, and http://dati.istat.it/?lang=en\#.

${ }^{2}$ Only recently have figures on immigrant-origin members of parliament been gathered systematically for a number of European countries as part of the Pathways to Power project (Morales et al. 2017). In this project, on which Vintila and Morales (2018) rely, members of parliament of immigrant origin are defined as those who (a) were born abroad as foreign nationals and who (may) have acquired the citizenship of the resident country (first generation) or (b) had one parent of foreign nationality at birth (second generation) (Morales et al. 2017, 3).
} 
to an estimated 6.7 per cent of the population (which includes citizen and non-citizen residents). From 1993 to 2016, most parliamentary representatives of immigrant origin came from other European countries (for example, France, Greece, Spain), followed by people from Latin America (Argentina and Dominican Republic) and African countries (mainly Algeria, Congo and Morocco); the latter two groups have been increasingly represented in the Italian parliament over the last 15 years (Vintila and Morales 2018).

\section{Moderation-of-Process Survey Experiment}

My theoretical arguments imply causal processes: to what extent can electoral discrimination toward candidates with a migration background be explained by the cognitive process of stereotyping? In other words, (how) do stereotypes mediate discrimination in elections? To test these arguments, I carried out an online survey experiment (see, for example, Mutz 2011). It is difficult to measure the causal mechanisms through which a treatment affects an outcome. My experimental approach is based on Spencer, Zanna and Fong (2005) and Acharya, Blackwell and Sen (2018), who propose an experimental design that provides some respondents with information on mediating variables and withholds this information from others.

\section{Participants}

My survey experiment was administered to a sample of 1,943 Italian citizens recruited by Dynata (formerly Research Now SSI) from 25 May through 3 June 2019. The sample is approximately representative of the general Italian population with respect to gender and age and includes only enfranchised Italian citizens. Since recent studies have shown that voters' left-right ideology or party preferences are related to electoral discrimination (Besco 2020; Portmann and Stojanović 2019; Street 2014), I assign subjects to the experimental conditions by blocking within strata defined by respondents' ideological positions (see Imai, King and Stuart 2008). Furthermore, because subjects were asked to evaluate a candidate from their preferred party, I focus my analysis on partisan respondents - those who indicated a party they 'feel close to'. ${ }^{3}$ As a result, out of the 1,943 respondents, 346 dropped out of the study and 1,597 observations are considered for the analysis (for an overview of the number of observations in the experimental groups, see Appendix Table 1). ${ }^{4}$

\section{Research Design and Procedure}

In the experiment, subjects are instructed to read a brief description of a person whom the party they feel closest to (henceforth labeled 'preferred party') is considering nominating (putatively based on the opinion of experts) as a candidate for upcoming national parliamentary elections (for the sake of simplicity, I sometimes refer to these 'potential candidates' simply as 'candidates').

An observable implication of stereotype-based theories is the following: if voters infer a candidate's characteristics based on his or her migration background, then voters should take the

\footnotetext{
${ }^{3}$ By excluding respondents who did not feel close to any party/movement, the results of this study can only be generalized to the entire electoral population to a limited extent. I expect that my estimates are rather conservative, in that discrimination might be more prevalent among non-partisans, who may be more willing to switch parties in order to support a preferred candidate.

${ }^{4}$ In my sample, forty-nine respondents (approximately 3 per cent) reported having a migration background. For these respondents, the candidate with a migration background may not always constitute an out-group candidate. The number of individuals with a migration background in my survey may only approximately reflect their actual share among the enfranchised Italian population (persons who hold Italian citizenship and who are of voting age) where they account for minimum 1 per cent according to a conservative estimate by Vintila and Morales (2018). The fact that the proportion of persons with a migration background in Italy is (still) relatively low both in the survey and in the enfranchised population suggests that any bias resulting from a potential imbalance regarding the inclusion of immigrant-origin individuals in this survey can be expected to be fairly small (for a discussion, see Barreto et al. 2018).
} 
migration background less into account when they receive explicit information about the inferred characteristics (see also Campbell et al. 2019). Put differently, providing voters with information counter-stereotypical information in particular - is expected to significantly over-ride the inferences made by voters (Conroy-Krutz 2013). To test the mediating effect of stereotypes, I analyze whether the effect of the candidate's name is smaller if positive information on the candidate is provided (when stereotyping should be disrupted), compared to situations in which such information is absent (for a similar approach, see Bor 2020 and Campbell et al. 2019). Therefore, in the vignettes I manipulate (1) the treatment, by altering the names of the candidates and (2) the mediator, by either providing or withholding a positive characterization of the candidate. The positive information about the candidate is counter-stereotypical in that it contradicts prevalent perceptions of immigrant-origin individuals.

I consider two sets of stereotypes: (1) those capturing traits and (2) those regarding 'civic citizenship'. The social psychology literature has predominantly focused on stereotypes regarding character traits ('trait stereotypes'). This research shows that sizable segments of the populations of European countries do not believe that immigrants act honestly and are law abiding, and perceive them as intrusive, lazy, and even (to some extent) prone to act violently (Lee and Fiske 2006; Sniderman and Hagendoorn 2007; Sniderman et al. 2000). Sociological research on boundary making and citizenship has highlighted the importance of ascriptions that portray immigrants as 'outsiders' who lack loyalty to their nation of residence (Bail 2008, 38; Simonsen and Bonikowski 2020; Sniderman and Hagendoorn 2007). These stereotypes propagate the notion in the electoral sphere that immigrant-origin candidates fail to live up to the civic culture that is constitutive for the nation ('civic citizenship stereotypes').

Based on this literature, I manipulate the purported mediating variable Stereotyping in the vignettes by positively describing the candidates' traits (as sincere, honest, respected and with a high level of expertise) and/or civic citizenship (as someone who promotes local and national Italian interests, values Italian culture and has a deep understanding of the country's political system). As described above, the positive information about the candidates (in terms of traits and/or civic citizenship) is expected to over-ride voters' stereotypes and decrease electoral discrimination. In the control condition (where stereotypes are not manipulated) the participants do not receive this positive description; they see only basic background information about the candidate, which is included in all vignettes. All four candidate descriptions are provided in Appendix Section B.1.

I manipulate the migration background of the fictitious candidate by presenting a name that is either typically Italian (Giuseppe Martinelli) or foreign (Ahmed Haddou). An Algerian name was chosen for the foreign name because (1) I expect that the name can be easily identified as foreign and (2) people from northern Africa make up a significant share of the immigrant-origin population in Italy, which has resulted in individuals from this group being referred to as the prototypical immigrant (Kosic, Mannetti and Sam 2005). In recent years, such individuals have started to gain access to both national and regional parliaments (Vintila and Morales 2018).

Two pilot studies conducted via Dynata on 18-19 April $2019(\mathrm{n}=442)$ and 3-8 May 2019 $(\mathrm{n}=242)$ confirmed that my treatment (candidate name) and manipulations of information are effective (for a more extensive discussion of the results from the pretests, see Appendix Section B.2).

In sum, my experimental design manipulates both the treatment, by describing a candidate with either an Italian $\left(T_{0}\right)$ or a foreign $\left(T_{1}\right)$ name $(T \in\{0,1\})$, and the mediator $\left(M_{i} \in\left\{m_{0}, m_{1}, m_{2}, m_{3}\right\}\right)$, by either providing or withholding information about candidates. While the baseline condition describes only the potential candidate's name, age and party affiliation $\left(m_{0}\right)$, other respondents also received a description that includes information about the candidate's positive character traits $\left(m_{1}\right)$, positive civic citizenship $\left(m_{2}\right)$ or both $\left(m_{3}\right)$. Hence, I employ a $2 \times 4$ factorial design that results in eight conditions to assess discrimination by comparing responses between subjects (see also Greenwald and Pettigrew 2014,678). After reading these vignettes, respondents answered questions about the degree to which they support or oppose the potential candidate $\left(Y_{i}\right)$. 
The indicated difference in electoral support between the candidate with an Algerian name and the candidate with an Italian name - absent any other information - corresponds to the average baseline effect of a candidate's migration background: $\operatorname{ABE}\left(t_{0}, t_{1}, m_{0}\right)=E\left[Y_{i}\left(t_{0}, m_{0}\right)-Y_{i}\left(t_{1}\right.\right.$, $\left.m_{0}\right)$ ]. Electoral discrimination is evident if the average baseline effect is non-zero - that is, if respondents treat the candidate with the Italian name differently from the one with the Algerian name. ${ }^{5}$

\section{Measurement of Dependent Variables}

As my first dependent variable, I measure (on an 11-point scale) how likely the respondent is to vote for the candidate in (putative) upcoming Italian national elections if he is nominated by the respondent's preferred party. Italy employs a parallel voting system, in which 37 per cent of the seats are allocated using a first-past-the-post system (FPTP) in single-member districts and 63 per cent via a proportional representation system in multi-member districts (see Garzia 2019). In the experiment I indicated that the potential candidate would run for a seat elected via FPTP. Because Italians can only cast their vote for a candidate if they vote for the candidate's party, they may face a trade-off between voting for their preferred party and for a specific candidate. I therefore include another dependent variable to check the robustness of the results (again measured on an 11-point scale), which captures the extent to which the respondent supports the proposition that his or her preferred party should nominate the candidate.

Refinements in the measurement of the dependent variables are needed in order to distinguish between 'discrimination against' and 'discrimination in favor of candidates. Such measures should be designed by 'including positive-, negative- and neutral-outcome conditions' (Hewstone, Rubin and Willis 2002, 579; see also Greenwald and Pettigrew 2014). Typically, studies that aim to disentangle in-group favoritism from out-group hostility provide the option to allocate positive stimuli to in-group members (for example, make monetary endowments), withdraw positive stimuli or allocate negative ones to the out-group (take away monetary endowments) and a neutral option (refrain from allocating and withdrawing monetary endowments) (see Buttelmann and Böhm 2014; De Dreu 2010; Halevy, Bornstein and Sagiv 2008). Accordingly, in the experiment, respondents were told that the researchers would forward an overall evaluation of the potential candidate to the party. They had the opportunity to give the potential candidate a positive, neutral or negative rating. A positive rating would increase the overall evaluation of the candidate, the negative rating would decrease it and the neutral rating would not influence the overall evaluation.

For the analysis, these responses were collapsed into two binary indicators. The first variable captures whether a respondent assigned a positive (1) or non-positive (that is, a negative or neutral) (0) rating. Likewise, the second variable takes a value of 1 for a negative rating and a value of 0 for those who cast a non-negative (positive or neutral) rating (descriptive statistics of the dependent variables are provided in Appendix Table 2, and Appendix Section C reports the question wording for all the dependent variables).

\section{Results}

In this section I first explore whether there is, in fact, evidence of electoral discrimination. Previous studies on electoral discrimination against candidates with a migration background suggest that discrimination occurs mainly among right-wing party voters (Besco 2020; Portmann and Stojanović 2019). Therefore, I analyze discrimination separately for different groups of respondents according to their ideological position (left, center, right). This inquiry is the

\footnotetext{
${ }^{5}$ Power analyses confirm that the sample size of the group $M_{i}=m_{0}(\mathrm{n}=202$ in each experimental group $)$ and considering the experimental groups within subgroups based on the ideological position of respondents (left, center, right) $(\mathrm{n}=50 \mathrm{in}$ each experimental group) yield sufficient levels of power to detect moderate effect sizes (Cohen 1988).
} 
basis for the subsequent section, which analyzes the mediating effect of stereotypes on this discrimination. Finally, I assess the prevalence and relationship of negative and positive stereotypes in the Italian population. All estimates in this article are obtained from linear regression models, while Appendix E provides results from logit models. Dependent variables are rescaled to a scale from 0 to 1 to facilitate interpretation of the results.

\section{The Effect of Candidate Names}

In order to explore electoral discrimination, I subset the data by only including respondents in the control condition who did not receive any further information about the candidate's character traits or civic citizenship. I consider that the effect of the candidate's name may depend on the ideological position of the respondent by including an interaction effect between the respondent's ideological position (left, center, right) and the name of the candidate (see Equation 1). The results on overall discrimination regardless of respondents' ideological positions are discussed in Appendix Section D. ${ }^{6}$

$$
Y_{i}=\beta_{0}+\beta_{1} \text { Cand.name }_{i}+\beta_{2} \text { Ideol }_{. i}+\beta_{3} \text { Cand.name }_{i} \text { XIdeol } . i+\beta_{4}\left(M_{i}=\text { Control }\right)+\epsilon_{i}
$$

Figure 1 presents estimates of the effect of a candidate's name on electoral support (and opposition) by respondents' ideological position. Following Brambor, Clark and Golder (2006)
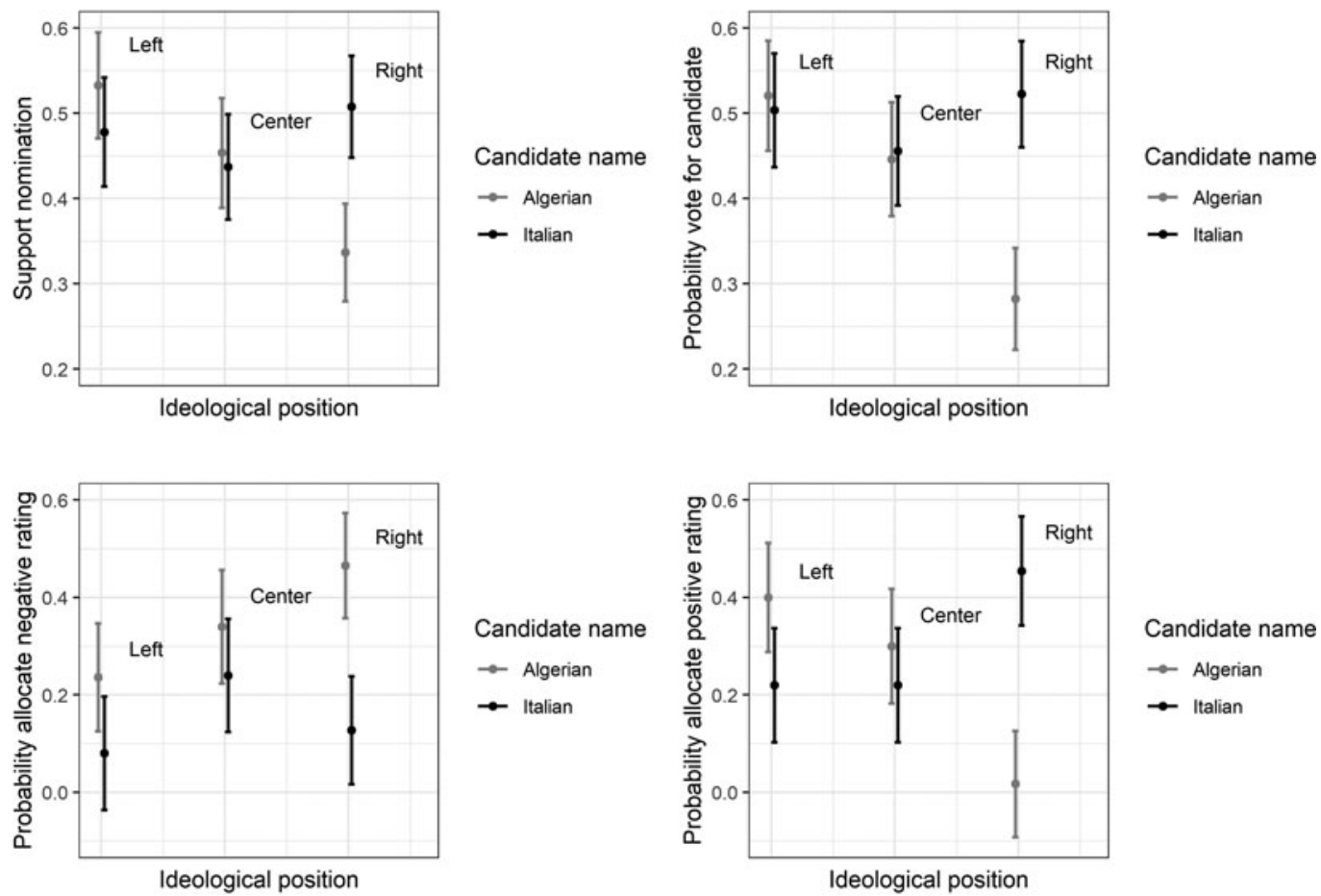

Figure 1. The effect of candidate names on electoral support and opposition, by ideological position of respondents Note: mean predicted values of the dependent variables and 95 per cent confidence intervals. All the dependent variables are re-scaled to a range $[0,1]$.

\footnotetext{
${ }^{6}$ Further analyses in this section of the Appendix provide evidence that the results regarding electoral discrimination are robust if generalized linear (instead of linear) models are estimated and when respondents of immigrant origin are excluded from the analyses.
} 
and Pepinsky (2018), I report predicted values of the dependent variables in the figure and provide regression output tables in Appendix Tables 7 and 8. In line with previous studies, the results provide strong evidence that electoral discrimination is related to a citizen's ideological position. The findings in Figure 1 show that it is primarily citizens who place themselves ideologically on the Right who discriminated against the candidate with the Algerian name. They were less likely to approve of their party nominating this candidate, and were less likely to report an intention to vote for this candidate should he run under the party's banner. Furthermore, the results in Figure 1 indicate that discrimination against the candidate with an Algerian name is prevalent among right-wing voters, although left and center voters show a tendency in this direction as well. Finally, I find that it is mainly right-wing respondents who discriminate in favor of the candidate with the Italian name. Citizens who position themselves ideologically on the left tend to even discriminate slightly in favor of the candidate with the Algerian name $(\mathrm{p}=0.030)$.

Overall, the findings strongly support the notion that the phenomenon of electoral discrimination is driven by citizens with a right-wing ideological attitude. Ideologically right-wing Italian citizens not only discriminate against immigrant-origin candidates; they also - as suggested by Hypothesis 1 - clearly discriminate in favor of majority candidates.

\section{Do Stereotypes Explain Electoral Discrimination?}

To assess the mediating effect of stereotyping, I again use linear regression and include a dummy for the treatment $\left(T_{i}\right)$ which captures the name of the candidate, a variable indicating the manipulation of the mediator $\left(M_{i}\right)$, and an interaction between the treatment and the manipulation of the mediator $\left(T_{i} M_{i}\right)$. The interaction effect indicates whether the effect of the candidate's name depends on the manipulation of information about the candidate (see Equation 2). I expect that differences in dependent variables between candidates with an Algerian vs. Italian name diminish in the treatment conditions - that is, when positive information about candidates is provided.

$$
Y_{i}=\beta_{0}+\beta_{1} \text { CandidateName }_{i}+\beta_{2} \text { Information }_{i}+\beta_{3} \text { CandidateName }_{i} \text { XInformation }_{i}+\epsilon_{i}
$$

Based on the finding that electoral discrimination differs considerably between respondents depending on their ideological position, I estimate the mediating effect of stereotypes for each subgroup (left, center, right) separately. Since discrimination seems to be largely driven by right-wing citizens, it is of particular relevance to determine whether stereotypes mediate electoral discrimination among those respondents.

Figure 2 reports predicted values of the dependent variables for each of the experimental conditions, focusing on respondents with ideologically center and left positions. The results indicate that, overall, stereotypes do not mediate the effect of the candidate's name among center and left-wing respondents: the difference between the two candidates is largely stable across experimental conditions. In fact, in all experimental conditions, there is no evidence that respondents treat the candidates differently. In other words, whether or not positive information about the candidates is provided, the results do not indicate electoral discrimination among left-wing and center respondents. This is the case for all dependent variables. Appendix Tables 9 and 10 confirm that the interaction effects do not reach the level of statistical significance. The only significant interaction effect in the models suggests that, among left-wing citizens, the candidate with the Algerian name seems to benefit somewhat less from a positive description regarding character traits with respect to the likelihood of being allocated a positive rating $(\mathrm{p}=0.039)$. Concretely, left-wing voters tend to adjust their tendency to discriminate in favor of the immigrant-origin candidate if candidates are described with positive traits. Overall, since left-wing 

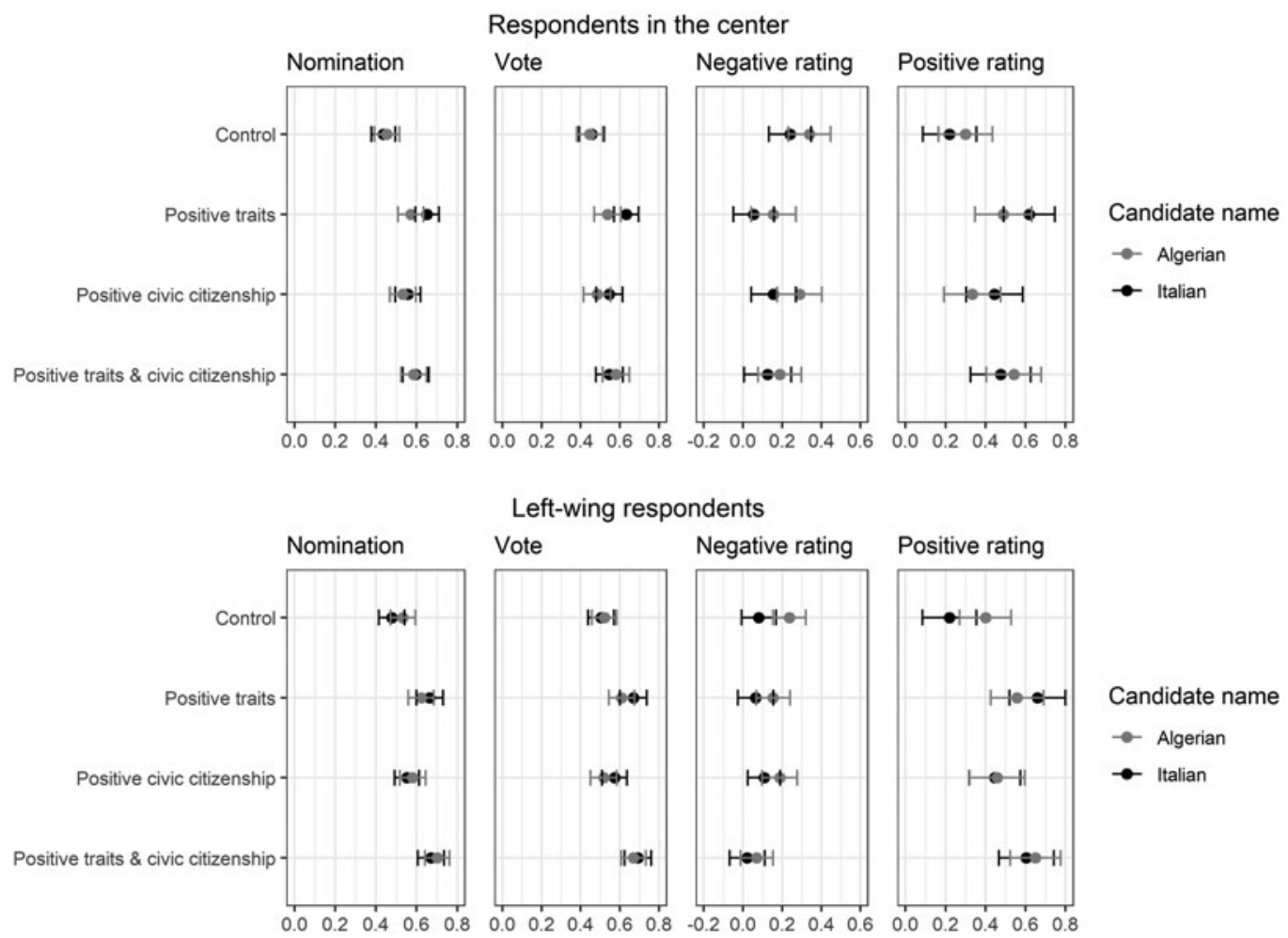

Figure 2. The mediating effect of stereotypes on electoral discrimination, ideologically left and center respondents Note: mean predicted values of the dependent variables and 95 per cent confidence intervals for the different experimental conditions. Center and left-wing respondents are included in the estimations. All the dependent variables are rescaled to a range $[0,1]$.

and center citizens, on average, did not discriminate against the immigrant-origin candidate in the first place, these results are rather unsurprising.

More interesting are the results concerning voters who position themselves on the right in the ideological spectrum. Discrimination in elections mainly occurs among this group of voters, as demonstrated in the previous section. Figure 3 reports the results on the mediating effect of stereotypes for respondents who hold right-wing ideological positions.

Interestingly, positive information about character traits and civic citizenship does not substantially influence electoral discrimination with respect to the likelihood that right-wing citizens will approve of nominating or vote for the candidate with a migration background. This is observable from the difference between the two candidates being largely comparable between the control and treatment conditions regarding these dependent variables. There is only a slight tendency for respondents to discriminate somewhat less if the candidates are positively described regarding civic citizenship, although the interaction effects do not reach the level of statistical significance for either support for nomination $(p=0.350)$ or likelihood to vote for the candidate $(p=0.175$; see also Appendix Table 11). Regardless of how the candidates are described, right-wing voters tend to approve of nominating the potential candidate with an Italian name more than they do the candidate with an Algerian name, and would be more likely to vote for him were he to be nominated. The results contradict the widespread assumption that stereotypes help explain discriminatory behavior among right-wing voters in elections. This finding is surprising, given that a broad literature has argued that stereotypes explain discrimination against racial minority candidates (see, for example, Piston 2010; Visalvanich 2017). 


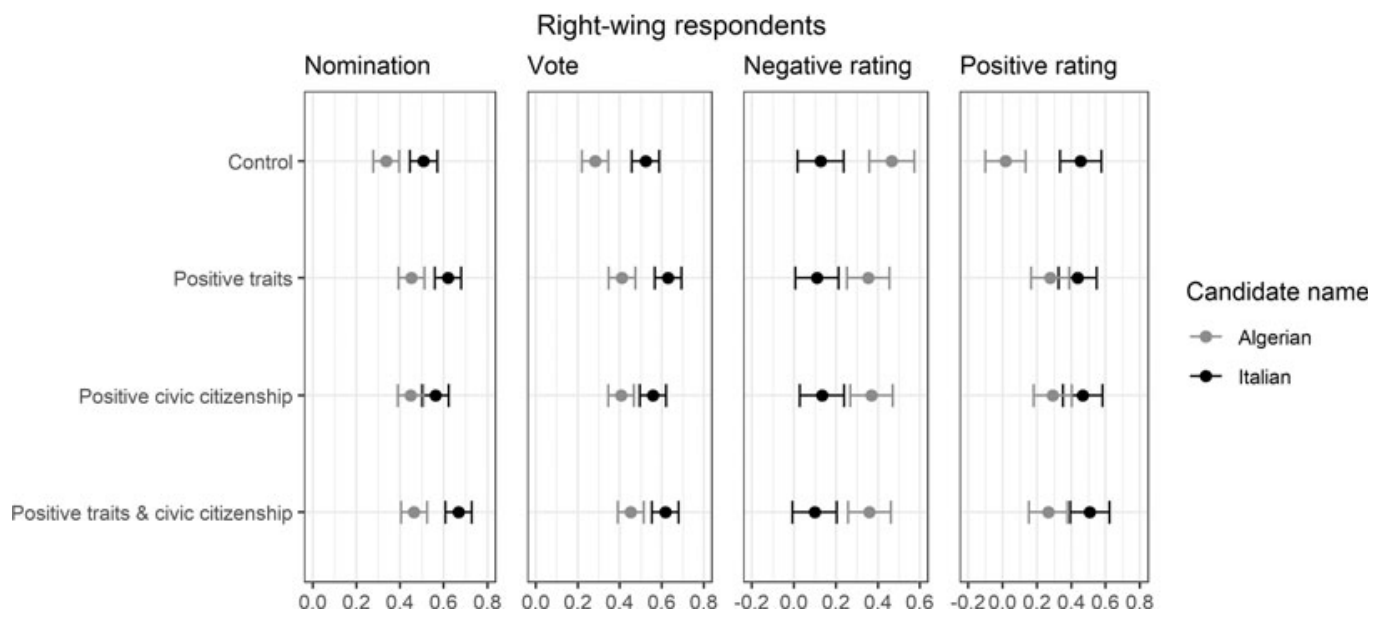

Figure 3. The mediating effect of stereotypes on electoral discrimination, ideologically right-wing respondents Note: mean predicted values of the dependent variables and 95 per cent confidence intervals for the different experimental conditions. Right-wing respondents are included in the estimations. All the dependent variables are rescaled to a range $[0,1]$.

In the next step, I explore the mediating effect of stereotypes concerning discrimination in favor of and discrimination against the candidates separately. Again, Figure 3 shows that in the scenario where these candidates are described positively regarding character traits and/or civic citizenship, citizens who place themselves ideologically on the right only slightly (not substantially) adjust their discriminatory tendency to return a negative rating ( $\mathrm{p}$-values $>0.1$ ). In all the experimental conditions, they are more willing to assign a negative rating to the potential candidate who has an Algerian name than to the one with an Italian name (see also the interaction effects which are not significant in Appendix Table 11).

By contrast, respondents are significantly more willing to also positively rate potential candidates with an Algerian name if they have further positive information on the candidates. Indeed, discrimination in favor of majority candidates is considerably reduced or even eliminated in the experimental conditions that positively describe the candidates. Put another way, absent any further information about the two candidates, Italian voters are more likely to give a positive rating to the candidate with the Italian name than to the one with an Algerian name; that is, they discriminate in favor of the majority candidate. However, when they are provided with further positive information about the candidates, they adjust their pro-in-group behavior, because then right-wing voters disproportionately increase their willingness to allocate a positive rating to the candidate with the migration background compared to the one with the Italian name. This information does not change respondents' likelihood of allocating a positive rating to the candidate with an Italian name, but it considerably impacts their likelihood of doing so if the candidate has an Algerian name. Thus providing positive information about candidates counters a pro-in-group bias, and decreases discrimination in favor of the majority candidates.

This finding is further corroborated by the result which shows that all three stereotypical manipulations mediate discrimination in favor of majority candidates in this way (see Figure 3 and Appendix Table 11). The mediating effect is clearest and most pronounced in conditions in which only traits $(\mathrm{p}=0.018)$ and civic citizenship $(\mathrm{p}=0.026)$ are manipulated; the interaction effect regarding the group with both positive character traits and civic citizenship information is statistically significant at the 0.1 level with a p-value of 0.099 . Overall, this means that right-wing Italian citizens in experimental conditions that included positive descriptions of the potential candidate adjusted their reluctance to allocate a positive rating to the immigrant-origin candidate compared to those in the control condition. These findings regarding right-wing citizens support 
Hypothesis 2, which expects that stereotypes mediate discrimination in favor of majority candidates.

Taken together, although overall stereotypes have little mediating effect on discrimination against immigrant-origin candidates in elections, they go some way toward explaining the stronger positive support for majority candidates (compared to those with a migration background) among right-wing Italian citizens. This suggests that other factors that remain largely immune to changes in the information environment (such as deeply rooted prejudices) may better explain discrimination against immigrant-origin candidates. However, the results also indicate that by providing positive information about candidates, right-wing parties can foster extra support for candidates with a migration background among some of their voters.

\section{The Prevalence of Positive and Negative Stereotypes}

My theoretical reasoning implies that positive stereotypes of the in-group support discrimination in favor of majority candidates, while negative ones of the out-group explain discrimination against minority candidates. How prevalent are these different forms of stereotypes?

The analysis of an Implicit Association Test (IAT) in which respondents participated at the end of the survey provides evidence that Italian citizens tend to associate candidates with Algerian names more strongly with negative characteristics and/or less strongly with positive ones than they do candidates with Italian names (see Appendix Sections F.1.1 and F.2.1). This analysis, however, does not allow me to determine the prevalence of positive stereotypes of majority candidates compared to negative stereotypes of minority candidates.

Therefore, I had respondents participate in an additional task after the experiment. Before they took part in the IAT they evaluated another set of two hypothetical candidates: one with an Italian name (Lorenzo Marino) and one with an Algerian name (Omar Zidane). The hypothetical candidates were presented in a randomly selected order regarding nine characteristics capturing traits and civic citizenship (Appendix Section G reports the complete survey flow including all questions). Each of the nine characteristics was presented on a separate bipolar scale ranging from the most negative (for example, incompetent) to the most positive (for example, competent). Appendix Figure 2 shows that Italian citizens, on average, rated both candidates positively with regard to most characteristics. However, the respondents' evaluations of the candidate with the Algerian name were, on average, consistently less positive (and regarding certain characteristics even slightly negative).

In order to assess positive and negative stereotypes at the individual level, I follow recent political science research that has used latent profile analysis to detect clusters in the data (Ahlquist and Breunig 2012; Alvarez, Levin and Núñez 2017). This approach serves to identify different groups of individuals in the sample who share similar stereotypes (for example, positive in-group stereotypes, negative out-group stereotypes or a combination thereof). Latent profile analysis is a form of cluster analysis that relies on mixture models (for a description see Appendix Section F.1.2). It identifies hidden groups (that is, profiles) in the data based on statistical models. One advantage of this approach is that the number of clusters can be determined by comparing different models (see Ahlquist and Breunig 2012). I compare Bayesian information criterion (BIC) scores to identify the model that best approximates the data (Ahlquist and Breunig 2012; see Appendix Table 13).

Applying this evaluation criteria results in a three-profile model solution. Figure 4 shows the estimated mean evaluation (and 95 per cent confidence intervals) regarding each characteristic for the three profiles derived from the model. The preferred model solution identifies two profiles that demonstrate a tendency to evaluate the candidate with the Italian name more favorably than the one with the Algerian name (see Profiles A and B in Figure 4). In the third profile (Profile C), which covers 3 per cent of the respondents, the evaluation does not observably vary in a consistent way with candidate names. Of the two profiles that display evident bias, both point towards an 


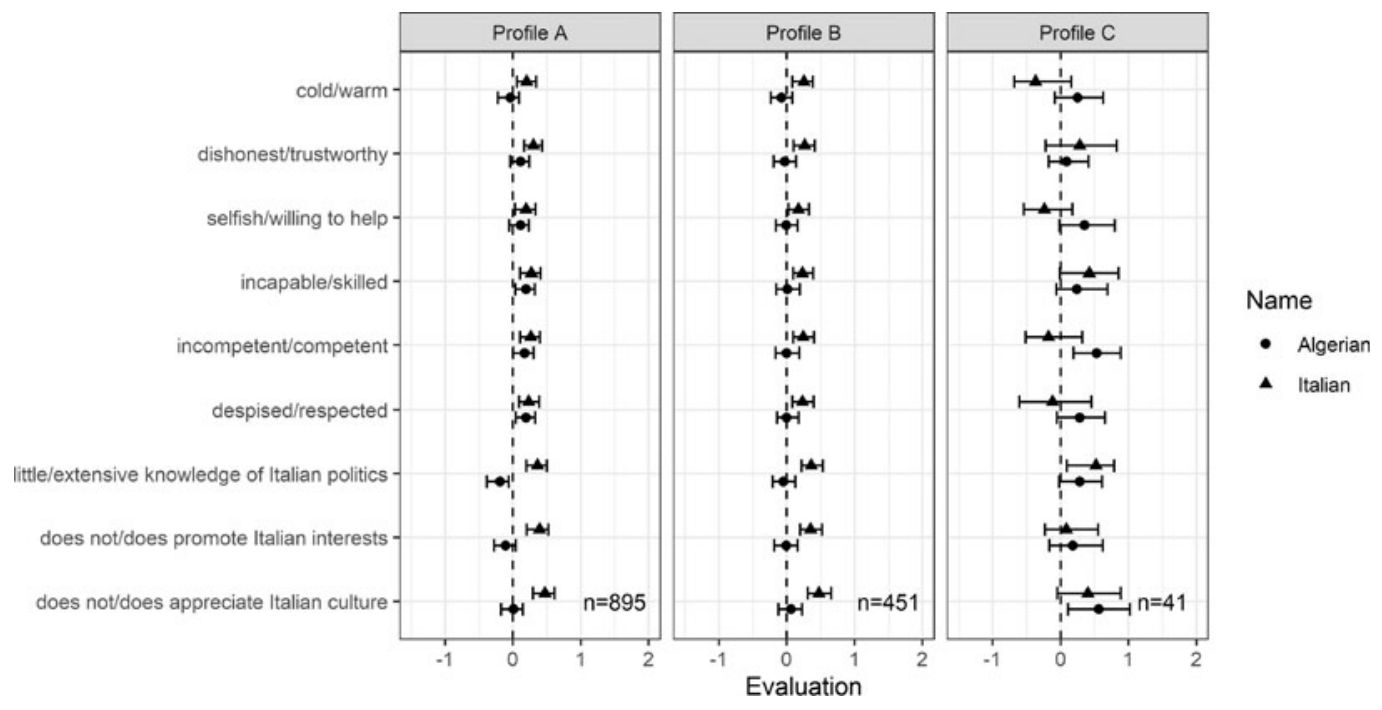

Figure 4. Evaluation of candidates (Algerian vs. Italian name) for the three profiles identified by latent profile analysis Note: the plot depicts mean ratings of traits and civic citizenship Surrounded by and 95 per cent confidence intervals. The three groups/ profiles are derived from latent profile analysis. Symbols indicate the name of the candidate (Algerian, Italian) that respondents rated. The respondents are distributed among the profiles as follows: Profile A (in-group favoritism regarding civic citizenship): 895 (65 per cent); Profile B (in-group favoritism general pattern): 451 (33 per cent); Profile C (unbiased/unclear pattern): 41 (3 per cent).

in-group favoritism. In the most prevalent profile (Profile A; 65 per cent of respondents), however, this tendency exists mainly for characteristics that capture civic citizenship (less so regarding character traits). With regard to these characteristics, respondents with this profile evaluate the candidate with an Algerian name neutrally (except with regard to 'knowledge of Italian politics', for which the evaluation is slightly negative) and the candidate with an Italian name positively. The other profile (33 per cent of respondents) reveals a surprisingly consistent picture of in-group favoritism. Regarding all characteristics, the immigrant-origin candidate is evaluated neutrally, but the majority candidate is rated positively (see Profile B).

Overall, these two approaches to measuring the pervasiveness and positive/negative valence of stereotypes provide strong evidence for the notion that stereotypes of immigrant-origin candidates are widespread in the Italian population. Specifically, the results suggest that a large share of respondents hold positive stereotypes of the majority candidate, but mostly without being negatively biased toward the immigrant-origin candidate.

\section{Conclusion}

Do candidates with a migration background incur an electoral penalty? What form does this discrimination take - a positive in-group bias or a negative out-group bias? And (how) can stereotype-based approaches help explain this electoral discrimination? Although the mediating role of stereotypes has attracted considerable attention in the political science literature on racial minority candidates, we know little about these questions as they pertain to immigrant-origin minorities. And despite widespread consensus in social psychological research that discrimination can result from both out-group hostility (discrimination against) and in-group favoritism (discrimination in favor of), the extant research on electoral discrimination has generally not distinguished between these two conceptualizations. The political behavior literature largely ignores the latter form of discrimination, which expresses itself by reserving benefits for the in-group. This article, therefore, crosses disciplinary boundaries and offers a new perspective on the study of electoral discrimination by including in-group favoritism in the research. 
In line with prior studies, I show that immigrant-origin candidates incur an electoral penalty, which is strongly driven by right-wing citizens. Can stereotype-based approaches help explain this electoral discrimination among right-wing individuals? Yes, but in a different way than has often been assumed. Providing citizens with positive information about candidates' character traits and civic citizenship - which is expected to counter stereotypes in the case of immigrantorigin candidates - does not substantially reduce discrimination against an immigrant-origin candidate. However, presenting these positive descriptions alongside candidates' names diminishes - in line with stereotype-based explanations - discrimination in favor of the majority candidate. These findings, which point to the importance of stereotypes in explaining discrimination in the form of in-group favoritism, are further corroborated by the results of a latent profile analysis. This additional analysis shows that a clear majority of Italian citizens holds positive stereotypes of majority candidates (which are expected to underlie discrimination in favor of such candidates) but is not negatively biased toward immigrant-origin candidates (that is, they evaluate the latter candidates in largely neutral terms).

This study adds to the literature on electoral discrimination in at least two respects. First, the findings highlight the importance of distinguishing between 'discrimination against' minority candidates and 'discrimination in favor of majority candidates, by showing that stereotypes mediate the latter form of discrimination in particular. Secondly, my results suggest that stereotypes about minority candidates are not solely negative; they often take the form of disproportionately less positive evaluations. This points to new paths for research, which has so far largely neglected the role that in-group favoritism among majority voters (those without a migration background) plays in explaining electoral behavior (for recent exceptions, see Jardina 2019; Jardina 2020; Petrow, Transue,and Vercellotti 2018).

I expect that findings from this research will, in important ways, inform the debate about strategies to combat discrimination against minority candidates. These strategies must not (only) aim to remedy the hostility and discrimination against candidates with a migration background; they should also address in-group favoritism. Parties and the media have the means to encourage positive perceptions of candidates who are members of a minority in order to increase support for these candidates (Gaertner and McLaughlin 1983, 5). My results indicate that, by contrast, de-emphasizing race and racial issues ('deracialization') may not be an effective strategy for winning votes if it only focuses on alleviating 'acting against' behaviors and beliefs, without promoting 'acting for' minority candidates (Sobolewska 2017, 228). Finally, attacking the roots of in-group favoritism will require measures that change social categorizations based on in-group vs. out-group members (Brewer 2017; Gaertner et al. 1993). In this vein, emphasizing goals and identities common to both people with a migration background and the majority population could help establish individuals with a migration background as part of the in-group (see also Ocampo 2018).

This study examines electoral discrimination using a candidate with an Algerian-sounding name in fictitious Italian elections. It is important to note that on Italian party ballots (at the regional, national and European levels) only a small minority of candidates have non-Italiansounding names, that is, names that indicate a migration background. And very few have Algerian names. Although this raises some questions about the external validity of this experiment, I would like to stress that it is likely (and desirable) that individuals with a migration background will be more represented among candidates in the future, in Italy and elsewhere. For this reason, and because questions about ethnic diversity in Western democracies are garnering increasing political interest (Sobolewska 2017, 235), addressing these issues is of growing importance.

Can my results be generalized to candidates with other, non-Algerian migration backgrounds? While some studies suggest that stereotyping and electoral discrimination differ depending on the immigrant-origin group in question (see, for example, Visalvanich 2017), other research shows that stereotypes affect various immigrant groups in a similar way (for example, Sniderman 
et al. 2000; Tajfel 1970, 96). As Sniderman et al. (2000, 143) note, 'a person who dislikes one group of immigrants is, to a striking degree, likely to dislike other groups of immigrants and is distinctly unlikely to come to the aid of one of these groups even if he dislikes another group more'. Future studies may want to devote more attention to analyzing electoral discrimination, and to the psychological or cognitive factors that explain it, with regard to specific groups of immigrant-origin candidates.

Finally, is Italy a special case in terms of the population's reactions to immigrants? On the one hand, it has a unique variation of xenophobia and nationalism. According to this view, the weakness of the state, the relatively late development of a national culture, and the parochial structure of Italian politics may have resulted in particularly exclusive definitions of an Italian identity and hostile reactions toward immigrants (Levy 2018, 51, 55; Sniderman et al. 2000). On the other hand, and without attempting to negate the specificity of these characteristics to Italy, it can also be argued that 'the alarms, concerns, prejudices and neuroses of the Italians were not that different from their neighbours' reactions' (Levy 2018, 51; see also Sniderman and Hagendoorn 2007). The generalizability of the results of this study is further supported by the fact that the findings regarding electoral discrimination among right-wing respondents are comparable to those of recent studies in other contexts (Besco 2020; Portmann and Stojanović 2019; Street 2014). Future studies should compare voters' electoral discrimination and stereotyping in different countries.

Supplementary material. Online appendices are available at https://doi.org/10.1017/S0007123420000800. The online appendix is organized as follows. A: Sample and data; B: Experimental manipulations; C: Measurement of dependent variables; D: Results regarding overall electoral discrimination; E: Regression output tables main analyses; F: The prevalence of positive and negative stereotypes; G: Survey text.

Acknowledgements. I would like to thank Tarik Abou-Chadi, Matt Barreto, Luca Bernardi, Alexander Bor, Andrea de Angelis, Diego Garzia, Anina Hanimann, Lasse Laustsen, Lusine Mkrtchyan, Angela X. Ocampo, Kristina Bakkær Simonsen, Rune Slothuus, Mark Stinson, Nenad Stojanović, Alexander Trechsel, Resul Umit, Bryan Wilcox-Archuleta, and three reviewers as well as participants of the following events for enriching discussions, helpful advice and feedback: a workshop and research stay at Aarhus University in November 2018, the Annual Conference of the Swiss Political Science Association 2019, the European Political Science Association Conference 2019, and the Workshop 'Political Representation in Democratic Systems' in August 2019 at the University of Zurich. I am grateful to Giada Crivelli and Melyssa Sigg for their excellent research assistance and Peter Cook's valuable support in editing the text.

Data availability statement. Replication data files are available in Harvard Dataverse at: https://doi.org/10.7910/DVN/ BNSXB2.

Financial support. This research was supported by the Swiss National Science Foundation (grant number: PZ00P1_ 154983) and the National Centre of Competence in Research (nccr - on the move) funded by the Swiss National Science Foundation (grant number: 51NF40-182897).

Ethical standards. All individuals who participated in the survey provided consent and were compensated for their participation.

\section{References}

Acharya A, Blackwell M and Sen M (2018) Analyzing causal mechanisms in survey experiments. Political Analysis 26(4), 357-378.

Ahlquist JS and Breunig C (2012) Model-Based clustering and typologies in the social sciences. Political Analysis 20, 92-112. Allport GW (1954) The Nature of Prejudice. Reading, MA: Addison-Wesley.

Alvarez RM, Levin I and Núñez L (2017) The four faces of political participation in Argentina: using latent class analysis to study political behavior. Journal of Politics 79(4), 1386-1402.

Bail CA (2008) The configuration of symbolic boundaries against immigrants in Europe. American Sociological Review 73, 37-59.

Balliet D, Wu J and De Dreu CKW (2014) Ingroup favoritism in cooperation: a meta-analysis. Psychological Bulletin 140(6), 1556-1581. 
Barreto MA et al. (2018) Best practices in collecting online data with Asian, Black, Latino, and White respondents: evidence from the 2016 Collaborative Multiracial Post-election Survey. Politics, Groups, and Identities 6(1), 171-180.

Besco R (2020) Friendly fire: electoral discrimination and ethnic minority candidates. Party Politics 26(2), 215-226.

Bizumic B et al. (2009) A cross-cultural investigation into a reconceptualization of ethnocentrism. European Journal of Social Psychology 39(6), 871-899.

Block R (2019) Racial stereotyping in political decision making. In Thompson WR (ed.), Oxford Research Encyclopedia of Politics. Oxford: Oxford University Press. https://doi.org/10.1093/acrefore/9780190228637.013.967.

Bor A (2020) Evolutionary leadership theory and economic voting: warmth and competence impressions mediate the effect of economic perceptions on vote. The Leadership Quarterly 31(2), 1-18.

Brambor T, Clark WR and Golder M (2006) Understanding interaction models: improving empirical analyses. Political Analysis 14, 63-82.

Brewer MB (1999) The psychology of prejudice: ingroup love or outgroup hate? Journal of Social Issues 55(3), 429-444.

Brewer MB (2017) Intergroup discrimination: ingroup love or outgroup hate? In Sibely CG and Barlow FK (eds), The Cambridge Handbook of the Psychology of Prejudice. Cambridge: Cambridge University Press, pp. 90-110.

Buttelmann D and Böhm R (2014) The ontogeny of the motivation that underlies in-group bias. Psychological Science 25(4), 921-927.

Campbell R, et al. (2019) Why friends and neighbors? Explaining the electoral appeal of local roots. Journal of Politics 81(3), 937-951.

Castelli Gattinara P (2017) The 'refugee crisis' in Italy as a crisis of legitimacy. Contemporary Italian Politics 9(3), 318-331.

Cohen J (1988) Statistical Power Analysis for the Behavioral Sciences, 2nd Edn. Hillsdale, NJ: Lawrence Erlbaum.

Conroy-Krutz J (2013) Information and ethnic politics in Africa. British Journal of Political Science 43(2), 345-373.

Dahl RA (2006) On Political Equality. New Haven, CT: Yale University Press.

Dancygier R et al. (2015) Why are immigrants underrepresented in politics? Evidence from Sweden. American Political Science Review 109(4), 703-724.

De Dreu CK (2010) Social value orientation moderates ingroup love but not outgroup hate in competitive intergroup conflict. Group Processes \& Intergroup Relations 13(6), 701-713.

De Figueiredo RJP and Elkins Z (2003) Are patriots bigots? An inquiry into the vices of in-group pride. American Journal of Political Science 47(1), 171-188.

Dovidio JF et al. (eds.) (2010) The SAGE Handbook of Prejudice, Stereotyping and Discrimination. Thousand Oaks, CA: Sage Publications.

Dovidio JF, Mann J and Gaertner SL (1989) Resistance to affirmative action: the implications of aversive racism. In Blanchard FA and Crosby FJ (eds), Affirmative Action in Perspective. New York: Springer, pp. 83-102.

Fischer R and Derham C (2016) Is in-group bias culture-dependent? A meta-analysis across 18 societies. SpringerPlus 5, 70 .

Fisher SD et al. (2015) Candidate ethnicity and vote choice in Britain. British Journal of Political Science 45(4), 883-905.

Fokkema T and de Haas H (2011) Pre- and post-migration determinants of socio-cultural integration of African immigrants in Italy and Spain. International Migration 53(6), 3-26.

Gaertner SL et al. (1993) The common ingroup identity model: recategorization and the reduction of intergroup bias. European Review of Social Psychology 4(1), 1-26.

Gaertner SL and McLaughlin JP (1983) Racial stereotypes: associations and ascriptions of positive and negative characteristics. Social Psychology Quarterly 46(1), 23-30.

Garzia D (2019) The Italian election of 2018 and the first populist government of Western Europe. West European Politics 42 (3), 670-680.

Greenwald AG and Pettigrew TF (2014) With malice toward none and charity for some: ingroup favoritism enables discrimination. American Psychologist 69(7), 669-684.

Halevy N, Bornstein G and Sagiv L (2008) 'In-group love' and 'out-group hate' as motives for individual participation in intergroup conflict: a new game paradigm. Psychological Science 19(4), 405-411.

Hamley L et al. (2020) Ingroup love or outgroup hate (or both)? Mapping distinct bias profiles in the population. Personality \& Social Psychology Bulletin 46(2), 171-188.

Hewstone M, Rubin M and Willis H (2002) Intergroup bias. Annual Review of Psychology 53, 575-604.

Imai K, King G and Stuart EA (2008) Misunderstandings between experimentalists and observationalists about causal inference. Journal of the Royal Statistical Society 171(2), 481-502.

Ivarsflaten E, Blinder S and Bjånesøy L (2020) How and why the populist radical right persuades citizens. In Suhay E, Grofman B and Trechsel AH (eds), The Oxford Handbook of Electoral Persuasion. Oxford: Oxford University Press, pp. 814-837.

Janssen C (2020) Shaping the (dis)advantage: the impact of partisan and demographic factors on ethnic minority candidates' success in preferential voting systems. Evidence from the Brussels case. Journal of Elections, Public Opinion and Parties. Doi: $10.1080 / 17457289.2020 .1746966$.

Jardina A (2019) White Identity Politics. Cambridge and New York: Cambridge University Press. 
Jardina A (2020) In-group love and out-group hate: white racial attitudes in contemporary U.S. elections. Political Behavior. Doi: $10.1007 / \mathrm{s} 11109-020-09600-\mathrm{x}$.

Kinder DR (2013) Prejudice and politics. In Huddy L, Sears DO and Levy JS (eds), The Oxford Handbook of Political Psychology, 2nd Edn. Oxford and New York: Oxford University Press, pp. 812-851.

Kosic A, Mannetti L and Sam DL (2005) The role of majority attitudes towards out-group in the perception of the acculturation strategies of immigrants. International Journal of Intercultural Relations 29(3), 273-288.

Lee TL and Fiske ST (2006) Not an outgroup, not yet an ingroup: immigrants in the stereotype content model. International Journal of Intercultural Relations 30, 751-768.

Levy C (2018) Racism, immigration, and new identities in Italy. In Mammone A and Parini EG (eds), The Routledge Handbook of Contemporary Italy. History, Politics, Society. Abingdon and New York: Routledge, pp. 49-63.

Lippert-Rasmussen K (ed.) (2018) The Routledge Handbook of the Ethics of Discrimination. London and New York: Routledge.

Lippmann W (1922) Public Opinion. New York: Macmillan.

Magni G (2020) Economic inequality, immigrants and selective solidarity: from perceived lack of opportunity to in-group favoritism. British Journal of Political Science. Doi: 10.1017/S0007123420000046.

McDermott ML (1998) Race and gender cues in low-information elections. Political Research Quarterly 51(4), 895-918.

Morales L, et al. (2017) Codebook and Data Collection Guidelines of Work Package 1 on Descriptive Political Representation in National Parliaments of the Project Pathways to Power. Technical report. Leicester: University of Leicester. Available from https://dataverse.harvard.edu/dataset.xhtml?persistentId=doi:10.7910/DVN/MRKJJF.

Mullen B, Brown R and Smith C (1992) Ingroup bias as a function of salience, relevance, and status: an integration. European Journal of Social Psychology 22(2), 103-122.

Mummendey A and Otten S (1998) Positive-negative asymmetry in social discrimination. European Review of Social Psychology 9(1), 107-143.

Mutz DC (2011) Population-Based Survey Experiments. Princeton, NJ: Princeton University Press.

Ocampo AX (2018) The Politics of Inclusion: A Sense of Belonging to US Society and Latino Political Participation. PhD thesis, University of California.

Oskooii KAR (2020) Perceived discrimination and political behavior. British Journal of Political Science 50(3), 867-892.

Pepinsky TB (2018) Visual heuristics for marginal effects plots. Research \& Politics 5(1), 1-9.

Petrow GA, Transue JE and Vercellotti T (2018) Do White in-group processes matter, too? White racial identity and support for Black political candidates. Political Behavior 40(1), 197-222.

Piston S (2010) How explicit racial prejudice hurt Obama in the 2008 election. Political Behavior 32(4), 431-451.

Portmann L and Stojanović N (2019) Electoral discrimination against immigrant-origin candidates. Political Behavior 41(1), 105-134.

Portmann L and Stojanović N (2021) Are Immigrant-Origin Candidates Penalized Due to Ingroup Favoritism or Outgroup Hostility? Comparative Political Studies. Forthcoming.

Portmann L (2020) Replication data for: Do stereotypes explain discrimination against minority candidates or discrimination in favor of majority candidates? https://doi.org/10.7910/DVN/BNSXB2, Harvard Dataverse, V1, UNF:6:1D6Up6LqXvq HU4Oe281E7g==[fileUNF]

Shah JY, Brazy PC and Higgins ET (2004) Promoting us or preventing them: regulatory focus and manifestations of intergroup bias. Personality \& Social Psychology Bulletin 30(4), 433-446.

Simonsen KB and Bonikowski B (2020) Is civic nationalism necessarily inclusive? Conceptions of nationhood and anti-Muslim attitudes in Europe. European Journal of Political Research 59, 114-136.

Sniderman P and Hagendoorn L (2007) When Ways of Life Collide: Multiculturalism and Its Discontents in the Netherlands. Princeton, NJ: Princeton University Press.

Sniderman PM et al. (2000) The Outsider: Prejudice and Politics in Italy. Princeton, NJ: Princeton University Press.

Sniderman PM et al. (2014) Paradoxes of Liberal Democracy: Islam, Western Europe, and the Danish Cartoon Crisis. Princeton, NJ: Princeton University Press.

Sniderman PM and Stiglitz EH (2008) Race and the moral character of the modern American experience. The Forum 6, 4.

Sobolewska M (2013) Party strategies and the descriptive representation of ethnic minorities: the 2010 British general election. West European Politics 36(3), 615-633.

Sobolewska M (2017) Race, ethnicity and elections: from recognizable patterns to generalized theories. In Arzheimer K, Evans J and Lewis-Beck MS (eds), The SAGE Handbook of Electoral Behavior, vol 1. London: Sage Publications, pp. 220-240.

Spencer SJ, Zanna MP and Fong GT (2005) Establishing a causal chain: why experiments are often more effective than mediational analyses in examining psychological processes. Journal of Personality and Social Psychology 89(6), 845-851.

Street A (2014) Representation despite discrimination: minority candidates in Germany. Political Research Quarterly 67(2), 374-385.

Tajfel H (1970) Experiments in intergroup discrimination. Scientific American 223(5), 96-103.

Thrasher M et al. (2017) Candidate ethnic origins and voter preferences: examining name discrimination in local elections in Britain. British Journal of Political Science 47(2), 413-435. 
Van Trappen S, Devroe R and Wauters B (2020) It is all in the eye of the beholder: an experimental study on political ethnic stereotypes in Flanders (Belgium). Representation 56(1), 31-51.

Venturini A (2004) Postwar Migration in Southern Europe, 1950-2000. An Economic Analysis. Cambridge: Cambridge University Press.

Vintila D and Morales L (2018) La Representación Política de las Personas de Origen Inmigrante en España e Italia [The Political Representation of Persons of Immigrant Origin in Spain and Italy]. Papers. Revista de sociologia 103(4), 521-550.

Visalvanich N (2017) When does race matter? Exploring White responses to minority congressional candidates. Politics, Groups, and Identities 5(4), 618-641.

Cite this article: Portmann L (2022). Do Stereotypes Explain Discrimination Against Minority Candidates or Discrimination in Favor of Majority Candidates? British Journal of Political Science 52, 501-519. https://doi.org/10.1017/S0007123420000800 